\title{
Green and expeditious synthesis of 1,8-dioxodecahydroacridine derivatives catalysed by protic pyridinium ionic liquid
}

\author{
HESHMATOLLAH ALINEZHAD ${ }^{\mathrm{a}, *}$, MAHMOOD TAJBAKHSH ${ }^{\mathrm{a}}$, \\ MOHAMMAD NOROUZI ${ }^{\mathrm{a}, \mathrm{b}}$, SAEED BAGHERY, ${ }^{\mathrm{c}}$ and JAMSHID RAKHTSHAH ${ }^{\mathrm{c}}$ \\ ${ }^{a}$ Department of Chemistry, Mazandaran University, Babolsar, Iran \\ ${ }^{b}$ Department of Chemistry, Payame Noor University, P.O. Box 19395-3697, Tehran, Iran \\ ${ }^{c}$ Department of Chemistry, College of Science, Bu-Ali Sina University, Hamedan, Iran \\ ${ }^{\mathrm{d}}$ Young Researchers Club, Science and Research Ayatollah Amoli Branch, \\ Islamic Azad University, Amol, Iran \\ e-mail: norouzimohammad346@yahoo.com
}

MS received 29 April 2013; revised 22 August 2013; accepted 23 August 2013

\begin{abstract}
The Hantzsch three-component condensation reaction of various aromatic aldehydes, 1,3-dione and aniline derivatives in the presence of 2-methylpyridinium trifluoromethanesulphonate ([2-MPyH]OTf) as green and highly efficient catalysts in water affords 1,8-dioxodecahydroacridine derivatives in good to excellent yields. This reaction has been carried out in the presence of $1 \mathrm{~mol} \%$ of [2-MPyH]OTf at room temperature. The described novel synthesis method proposes several advantages of mild condition, short reaction times, high yields, simplicity and easy workup compared to the traditional method of synthesis.
\end{abstract}

Keywords. 2-Methylpyridinium trifluoromethanesulphonate; Hantzsch three-component condensation; protic ionic liquid; 1,8-dioxodecahydroacridine; water solvent.

\section{Introduction}

Ionic liquids (ILs) are salts consisting of ions, which exist in the liquid state at ambient temperatures. ${ }^{1}$ They show reasonably high ionic conductivities. Although the first IL, ethyl ammonium nitrate (M.p. $12^{\circ} \mathrm{C}$ ) was reported as early as $1914,{ }^{2}$ ILs have generated great interest only recently. ILs are usually characterized by a wide electrochemical window of stability, a reasonable ionic conductivity (similar to most non-aqueous electrolytes). ILs typically consist of organic nitrogencontaining heterocyclic cations and inorganic anions. ${ }^{1}$ Nevertheless, in the last few years, they have become more attractive in other fields such as catalysis, ${ }^{3}$ formation of metal nanostructures, ${ }^{4}$ analytical chemistry ${ }^{5}$ including sensors ${ }^{6}$ and for electrochemical biosensors. ${ }^{7}$ Due to their high polarities, ILs are expected to be suitable solvents for the reaction between organo-soluble and water soluble reagents. ${ }^{8}$

Acridine and its derivatives are interesting compounds, because of their well-known properties in fields of medicinal ${ }^{9,10}$ and biological activities (such as anticancer, ${ }^{11}$ antibacterial, ${ }^{12}$ antitumour, ${ }^{13}$ anticonvulsant, ${ }^{14}$ antimalarial, ${ }^{15}$ analgesic, ${ }^{16}$ hypertensive and

*For correspondence anti-inflammatory), ${ }^{17}$ applications in material science (semiconductors) ${ }^{18}$ and spectroscopy (luminescent agent). ${ }^{19}$ Therefore, their syntheses have attracted a large number of organic chemists. ${ }^{20}$

Preparation of acridine and its derivatives is a threecomponent reaction which is an important class of organic reactions. Many procedures have explained the synthesis of acridine derivatives containing 1,4dihydropyridines, from dimedone, aldehydes and different nitrogen sources such as urea, ${ }^{21}$ ceric ammonium nitrate, ${ }^{22}$ ammonium acetate on basic alumina, ${ }^{23}$ and different appropriate amines or ammonium acetate, ${ }^{24}$ via conventional heating in organic solvents, in the presence of Amberlyst-15, ${ }^{25} p$ dodecylbenzenesulphonic acid (DBSA), ${ }^{26}$ triethylbenzylammonium chloride (TEBAC) ${ }^{27}$ and using $\mathrm{ILs}^{28-30}$ such as Brønsted acidic imidazolium salts containing perfluoroalkyl tails, ${ }^{31} 1$-methylimidazolium triflouroacetate ([Hmim]Tfa). ${ }^{32}$

However, some of the reported methods of synthesis of 1,8-dioxodecahydroacridine involve unpleasant experimental procedure and reagents which are expensive. A mild and efficient catalyst for the synthesis of 1,8-dioxodecahydroacridine is very desirable. Performing organic reactions in aqueous media has attracted much attention because of the wonderful properties 

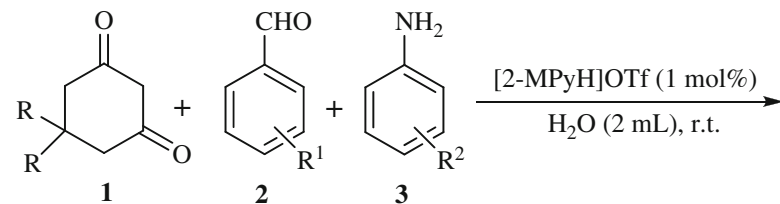

Catalyst: [2-MPyH]OTf
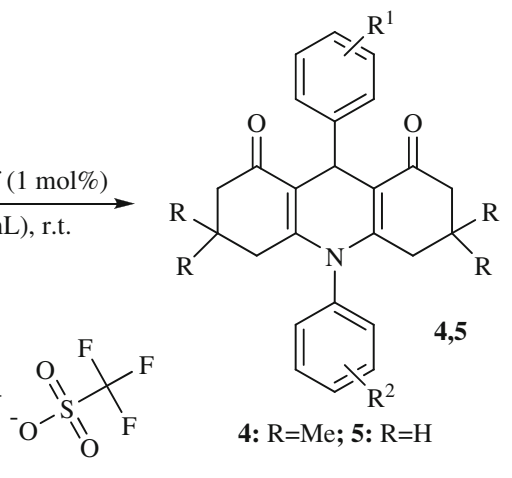

Scheme 1. Synthesis of 1,8-dioxodecahydroacridines catalysed by protic pyridinium ionic liquid.

of water. It would be significantly safe, cheap, nontoxic and environment-friendly compared to organic solvents. ${ }^{33}$

In 2006, Deng et al. ${ }^{34}$ introduced new functionalized acidic ILs based on pyridinium which have much higher activity than other reported catalysts with the additional advantage of reusability. In this article, we wish to report a green and highly efficient method for onepot synthesis of 1,8-dioxodecahydroacridine derivatives via Hantzsch three-component condensation reaction using an IL as catalyst. This is an efficient synthesis in aqueous media, which not only defends simplicity but also constantly gives corresponding products in good to excellent yields (scheme 1).

\section{Experimental}

\subsection{General procedure for synthesis of [2-MPyH]OTf} as a IL catalyst

The IL [2-MPyH]OTf as a catalyst was synthesized according to literature. ${ }^{34} \mathrm{~A}$ white solid was formed in high purity and then the physical data (IR, NMR) of these known ILs was found to be identical. Spectral data: ${ }^{1} \mathrm{H}$ NMR $\left(400 \mathrm{MHz}, \mathrm{CDCl}_{3}\right): \delta 2.93(\mathrm{~s}, 3 \mathrm{H}), 7.26-$ $7.67(\mathrm{~m}, 2 \mathrm{H}), 8.29-8.36(\mathrm{~m}, 1 \mathrm{H}), 8.84(\mathrm{~d}, J=5.9 \mathrm{~Hz}$, 1H), 17.21 (brs, $1 \mathrm{H}) ;{ }^{13} \mathrm{C} \mathrm{NMR}\left(100 \mathrm{MHz}, \mathrm{CDCl}_{3}\right): \delta$ 154.1, 146.7, 141.3, 128.1, 125.3, 120.7, 21.1; IR (KBr, $\mathrm{cm}^{-1}$ ) 2983, 1631, 1365, 1223, 1070, 957, 887, 579.

\subsection{Recycling of [2-MPyH]OTf as an IL catalyst}

In case of a hydrophilic ionic liquid, i.e., [2-MPyH]OTf, the reaction mixture was diluted with water and extracted with $\mathrm{CH}_{2} \mathrm{Cl}_{2}(2 * 10 \mathrm{~mL})$. The combined organic extracts were washed with water, dried over anhydrous $\mathrm{Na}_{2} \mathrm{SO}_{4}$, concentrated under vacuum and the resulting product was purified by recrystallization to afford pure product. The ionic liquid can be recovered either by extracting the aqueous phase with $\mathrm{CH}_{2} \mathrm{Cl}_{2}$ or by evaporating the aqueous layer under vacuum. The ionic liquid thus obtained was further dried at $60^{\circ} \mathrm{C}$ under reduced pressure for use in subsequent runs.

\subsection{General procedure for the synthesis} of 1,8-dioxodecahydroacridine derivatives

A mixture of an aromatic aldehyde (1.0 mmol), 1, 3dione $(2.0 \mathrm{mmol})$, aniline derivatives $(1.0 \mathrm{mmol})$ and ILs as a catalyst $(1 \mathrm{~mol} \%)$ in water $(2 \mathrm{~mL})$ was stirred at room temperature for an appropriate time. The progress of the reaction was monitored by TLC. After completion of the reactions, the mixture solid was filtered off and washed with $\mathrm{H}_{2} \mathrm{O}(10 \mathrm{~mL})$ and the crude products were obtained. The crude products were purified by recrystallization from ethanol (98\%).

\subsection{Spectral data for the synthesis of 1,8-dioxodecahydroacridine derivatives}

2.4a 3,3,6,6-Tetramethyl-9-(4-chlorophenyl)-10-phenyl3,4,6,7,9,10-hexahydroacridine-1,8(2H,5H)-dione (table 1, entry $4 b$ ): M.p. $243-245^{\circ} \mathrm{C}$ (lit. ${ }^{30} 244-246{ }^{\circ} \mathrm{C}$ ); ${ }^{1} \mathrm{H}$ NMR spectrum $\left(400 \mathrm{MHz}, \mathrm{CDCl}_{3}, \delta, \mathrm{ppm}\right): 1.65$ (s, $\left.6 \mathrm{H}, 2 * \mathrm{CH}_{3}\right), 1.83\left(\mathrm{~s}, 6 \mathrm{H}, 2 * \mathrm{CH}_{3}\right), 2.54(\mathrm{dd}, 4 \mathrm{H}$, $\left.J=16.1 \mathrm{~Hz}, 2 * \mathrm{CH}_{2}\right), 2.75(\mathrm{dd}, 4 \mathrm{H}, J=16.3 \mathrm{~Hz}$, $\left.2 * \mathrm{CH}_{2}\right), 5.17(\mathrm{~s}, 1 \mathrm{H}, \mathrm{CH}), 7.23-7.37(\mathrm{~m}, 5 \mathrm{H}, \mathrm{ArH})$, $7.53(\mathrm{~d}, 2 \mathrm{H}, J=9.3 \mathrm{~Hz}, \operatorname{ArH}), 7.67(\mathrm{~d}, J=9.2 \mathrm{~Hz}$, $2 \mathrm{H}, \mathrm{ArH})$; IR spectrum $\left(\mathrm{KBr}, v, \mathrm{~cm}^{-1}\right): 785(-\mathrm{CH}$ out of bending of aromatic ring), 1235 (CN stretching $), 1375,1575(\mathrm{C}=\mathrm{C}-$ stretching of aromatic ring $)$, $1671(\mathrm{C}=\mathrm{O}-$ of 1,3 -diketone), 2945 ( $\mathrm{CH}$ stretching of aliphatic), 3055 ( $-\mathrm{CH}$ stretching of aromatic ring). 
Table 1. Synthesis of 1,8-dioxodecahydroacridine derivatives catalysed by ionic liquid in water ${ }^{\mathrm{a}}$.

\begin{tabular}{|c|c|c|c|c|c|}
\hline Entry & $\mathrm{R}^{1}$ & $\mathrm{R}^{2}$ & Time (min) & Yield $(\%)^{b}$ & M.p $\left({ }^{\circ} \mathrm{C}\right)$ [Ref.] \\
\hline $4 \mathbf{a}$ & $\mathrm{H}$ & $\mathrm{H}$ & 15 & 94 & $255-257^{25}$ \\
\hline $4 b$ & $4-\mathrm{Cl}$ & $\mathrm{H}$ & 11 & 96 & $243-245^{30}$ \\
\hline $4 c$ & 4-OMe & $\mathrm{H}$ & 11 & 94 & $222-224^{25}$ \\
\hline $4 d$ & $3-\mathrm{NO}_{2}$ & $\mathrm{H}$ & 5 & 98 & $297-299^{22}$ \\
\hline $4 e$ & $\mathrm{H}$ & 4-Me & 11 & 94 & $223-285^{26}$ \\
\hline $4 f$ & $2-\mathrm{Cl}$ & 4-Me & 11 & 95 & $284-286^{26}$ \\
\hline $4 g$ & $3-\mathrm{Cl}$ & 4-Me & 9 & 95 & $316-318^{26}$ \\
\hline $4 h$ & $4-\mathrm{Cl}$ & 4-Me & 8 & 96 & $273-275^{26}$ \\
\hline $4 \mathbf{i}$ & $2,4-\mathrm{Cl}_{2}$ & 4-Me & 9 & 95 & $318-320^{26}$ \\
\hline $4 j$ & $3,4-\mathrm{Cl}_{2}$ & 4-Me & 9 & 96 & $251-253^{30}$ \\
\hline $4 \mathbf{k}$ & 4-Me & 4-Me & 8 & 96 & $295-297^{30}$ \\
\hline 41 & 4-OH & 4-Me & 10 & 94 & $347-349^{26}$ \\
\hline $4 m$ & 4-OMe & 4-Me & 8 & 95 & $279-281^{26}$ \\
\hline $4 n$ & 4-OH-3-OMe & 4-Me & 9 & 94 & $273-275^{26}$ \\
\hline 40 & $3-\mathrm{NO}_{2}$ & 4-Me & 3 & 98 & $285-287^{26}$ \\
\hline $4 p$ & $\mathrm{H}$ & 4-OMe & 11 & 95 & $214-216^{31}$ \\
\hline $4 q$ & 4-Cl & 4-OMe & 7 & 96 & $252-254^{31}$ \\
\hline $4 r$ & 4-OMe & 4-OMe & 8 & 96 & $210-212^{31}$ \\
\hline $4 s$ & $2-\mathrm{Cl}$ & 4-Cl & 9 & 95 & $315-317^{35}$ \\
\hline $4 t$ & $4-\mathrm{Cl}$ & $4-\mathrm{Cl}$ & 7 & 97 & $303-305^{35}$ \\
\hline $4 u$ & $\mathrm{H}$ & $4-\mathrm{Br}$ & 10 & 95 & $270-272^{35}$ \\
\hline $5 \mathbf{a}$ & $\mathrm{H}$ & $\mathrm{H}$ & 20 & 91 & $275-277^{36}$ \\
\hline $5 b$ & 4-Cl & $\mathrm{H}$ & 15 & 94 & $291-293^{22}$ \\
\hline $5 c$ & $3-\mathrm{NO}_{2}$ & $\mathrm{H}$ & 8 & 95 & $277-279^{22}$ \\
\hline $5 d$ & 2-OMe & $\mathrm{H}$ & 15 & 92 & $267-267^{37}$ \\
\hline
\end{tabular}

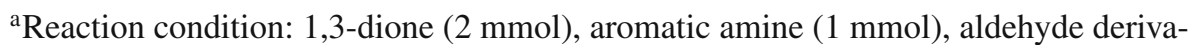
tives $(1 \mathrm{mmol})$, ionic liquid catalyst $(1 \mathrm{~mol} \%)$, water solvent $(2 \mathrm{~mL})$

${ }^{\mathrm{b}}$ Isolated yield

$2.4 \mathrm{~b}$ 9-(4-Hydroxyphenyl)-3,3,6,6-tetramethyl-10-ptolyl-3,4,6,7,9,10-hexahydroacridine-1,8(2H,5H)-dione (table 1, entry $4 \mathrm{~m}$ ): $\quad$ M.p. $279-281^{\circ} \mathrm{C}$ (lit. ${ }^{26} 282-383^{\circ} \mathrm{C}$ ); ${ }^{1} \mathrm{H}$ NMR spectrum $\left(400 \mathrm{MHz}, \mathrm{CDCl}_{3}, \delta, \mathrm{ppm}\right): 1.74$ $\left(\mathrm{s}, 6 \mathrm{H}, 2 * \mathrm{CH}_{3}\right), 1.83\left(\mathrm{~s}, 6 \mathrm{H}, 2 * \mathrm{CH}_{3}\right), 2.27(\mathrm{~s}, 3 \mathrm{H}$, $\left.\mathrm{CH}_{3}\right), 2.45\left(\mathrm{dd}, 4 \mathrm{H}, J=16.8 \mathrm{~Hz}, 2 * \mathrm{CH}_{2}\right), 2.63(\mathrm{dd}$, $\left.4 \mathrm{H}, J=16.9 \mathrm{~Hz}, 2^{*} \mathrm{CH}_{2}\right), 5.23(\mathrm{~s}, 1 \mathrm{H}, \mathrm{CH}), 5.47(\mathrm{~s}$, $1 \mathrm{H}, \mathrm{OH}), 7.26(\mathrm{~d}, 2 \mathrm{H}, J=9.2 \mathrm{~Hz}, \mathrm{ArH}), 7.37(\mathrm{~d}, 2 \mathrm{H}$, $J=9.3 \mathrm{~Hz}, \operatorname{ArH}), 7.56(\mathrm{~d}, 2 \mathrm{H}, J=9.3 \mathrm{~Hz}, \operatorname{ArH})$, $7.64(\mathrm{~d}, 2 \mathrm{H}, J=9.3 \mathrm{~Hz}, \mathrm{ArH})$; IR spectrum (KBr, $v$, $\mathrm{cm}^{-1}$ ): 780 ( $-\mathrm{CH}$ out of bending of aromatic ring), 1230 (CN stretching), 1370, $1567(\mathrm{C}=\mathrm{C}-$ stretching of aromatic ring), $1659(\mathrm{C}=\mathrm{O}-$ of 1,3-diketone $), 2945$ (CH stretching of aliphatic), 3057 ( $-\mathrm{CH}$ stretching of aromatic ring), 3581 (OH stretching).

2.4c 10-(4-Methoxyphenyl)-3,3,6,6-tetramethyl-9phenyl-3,4,6,7,9,10-hexahydroacridine-1,8(2H,5H)dione (table 1, entry $4 p$ ): M.p. $214-216^{\circ} \mathrm{C}$ (lit. ${ }^{31}$ 215-217 $\left.{ }^{\circ} \mathrm{C}\right) ;{ }^{1} \mathrm{H}$ NMR spectrum $\left(400 \mathrm{MHz}, \mathrm{CDCl}_{3}\right.$, $\delta, \mathrm{ppm}): 1.71\left(\mathrm{~s}, 6 \mathrm{H}, 2 * \mathrm{CH}_{3}\right), 1.77\left(\mathrm{~s}, 6 \mathrm{H}, 2 * \mathrm{CH}_{3}\right)$, $2.29\left(\mathrm{dd}, 4 \mathrm{H}, J=16.2 \mathrm{~Hz}, 2 * \mathrm{CH}_{2}\right), 2.35(\mathrm{dd}, 4 \mathrm{H}$, $\left.J=16.1 \mathrm{~Hz}, 2 * \mathrm{CH}_{2}\right), 3.75\left(\mathrm{~s}, 3 \mathrm{H}, \mathrm{CH}_{3}\right), 5.12(\mathrm{~s}, 1 \mathrm{H}$, $\mathrm{CH}), 7.25(\mathrm{~d}, 2 \mathrm{H}, J=9.2 \mathrm{~Hz}, \operatorname{ArH}), 7.33-7.38(\mathrm{~m}$, $5 \mathrm{H}, \mathrm{ArH}), 7.43$ (d, 2H, $J=9.2 \mathrm{~Hz}, \mathrm{ArH})$; IR spectrum $\left(\mathrm{KBr}, v, \mathrm{~cm}^{-1}\right)$ : $980(-\mathrm{CH}$ out of bending of aromatic ring), 1230 (CN stretching), 1335 (C-O stretching), $1357,1560(\mathrm{C}=\mathrm{C}-$ stretching of aromatic ring $), 1679$ ( $\mathrm{C}=\mathrm{O}-$ of 1,3-diketone), 2955 ( $\mathrm{CH}$ stretching of aliphatic), 3065 ( $-\mathrm{CH}$ stretching of aromatic ring).

2.4d 10-(4-Bromophenyl)-3,3,6,6-tetramethyl-9-phenyl3,4,6,7,9,10-hexahydroacridine-1,8(2H,5H)-dione (table 1, entry $4 u$ ): M.p. $270-272{ }^{\circ} \mathrm{C}$ (lit. ${ }^{22} 269-272{ }^{\circ} \mathrm{C}$ ); ${ }^{1} \mathrm{H}$ NMR spectrum $\left(400 \mathrm{MHz}, \mathrm{CDCl}_{3}, \delta, \mathrm{ppm}\right): 1.73$ (s, $\left.6 \mathrm{H}, 2 * \mathrm{CH}_{3}\right), 1.81\left(\mathrm{~s}, 6 \mathrm{H}, 2 * \mathrm{CH}_{3}\right), 2.37(\mathrm{dd}, 4 \mathrm{H}$, $\left.J=16.2 \mathrm{~Hz}, 2 * \mathrm{CH}_{2}\right), 2.44(\mathrm{dd}, 4 \mathrm{H}, J=16.3 \mathrm{~Hz}$, $\left.2 * \mathrm{CH}_{2}\right), 5.36(\mathrm{~s}, 1 \mathrm{H}, \mathrm{CH}), 7.21-7.35(\mathrm{~m}, 5 \mathrm{H}, \mathrm{ArH})$, $7.38(\mathrm{~d}, 2 \mathrm{H}, J=9.1 \mathrm{~Hz}, \operatorname{ArH}), 7.51(\mathrm{~d}, 2 \mathrm{H}, J=$ $9.3 \mathrm{~Hz}, \mathrm{ArH})$; IR spectrum $\left(\mathrm{KBr}, v, \mathrm{~cm}^{-1}\right): 778(-\mathrm{CH}$ out of bending of aromatic ring), 1225 (CN stretching), $1367,1545(\mathrm{C}=\mathrm{C}-$ stretching of aromatic ring), 
$1671(\mathrm{C}=\mathrm{O}-$ of 1,3-diketone), 2953 ( $\mathrm{CH}$ stretching of aliphatic), 3065 ( $-\mathrm{CH}$ stretching of aromatic ring).

\section{Results and discussion}

\subsection{Effect of reaction conditions}

To study the generality of this process, several examples illustrating this method for the synthesis of those polyfunctionalized 1,8-dioxodecahydroacridines were studied. Results are summarized in table 1 . The effect of electron and the nature of substituents on the aromatic ring did showed expected strong effects in terms of yields under these reaction conditions. Aromatic aldehydes and aniline derivatives containing electron-withdrawing groups (such as nitro and halo groups) or electron-donating groups (such as hydroxyl and alkoxyl groups) were employed and they were found to react well to give the corresponding 1,8-dioxodecahydroacridines in good to excellent yields. Aromatic aldehydes having electronwithdrawing groups on the aromatic ring (table 1, entries 3d, 3h, 3o) react faster than electron-donating groups (table 1, entries 3c, 31, 3m, 3r). Also, aniline derivatives similarly underwent the conversion well. Also, the reaction in the presence of 5,5dimethylcyclohexane-1,3-dione occurs faster than the reaction in presence of cyclohexane-1,3-dione.

\subsection{Effect of solvent, amount of catalyst and temperature}

We have also examined the effects of the solvent through a few experiments. As a model reaction, the reaction of 4-chlorobenzaldehyde with 5,5dimethylcyclohexane-1,3-dione and $p$-toluidine catalysed by $1 \mathrm{~mol} \%$ IL in various solvents are summarized in table 2 . The yields refer to the isolated yields. From table 2, we know that water is obviously the best choice for these reactions. Another reason we chose water as the solvent of this reaction is that water is safe,

Table 2. Reaction in various solvents catalysed by ionic liquid $^{\mathrm{a}}$.

\begin{tabular}{lccccc}
\hline Solvent & $\mathrm{H}_{2} \mathrm{O}$ & $\mathrm{C}_{2} \mathrm{H}_{5} \mathrm{OH}$ & $\mathrm{CH}_{3} \mathrm{CN}$ & Toluene & Benzene \\
\hline Time (min) & 8 & 10 & 15 & 25 & 31 \\
Yield (\%) & 96 & 96 & 94 & 89 & 89 \\
\hline
\end{tabular}

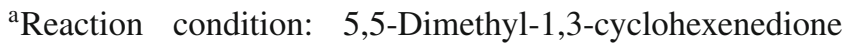
(2 mmol), $p$-toluidine (1 mmol), 4-chlorobenzaldehyde (1 mmol), ionic liquid catalyst ( $1 \mathrm{~mol} \%)$, solvent $(2 \mathrm{~mL})$

${ }^{\mathrm{b}}$ Isolated yield.
Table 3. Optimization reaction condition for preparation of acridine ${ }^{\mathrm{a}}$.

\begin{tabular}{lcccc}
\hline Entry & $\begin{array}{c}\text { Catalyst amount } \\
(\mathrm{mol} \%)\end{array}$ & $\begin{array}{c}\text { Temperature } \\
\left({ }^{\circ} \mathrm{C}\right)\end{array}$ & $\begin{array}{c}\text { Time } \\
(\mathrm{min})\end{array}$ & $\begin{array}{c}\text { Yield } \\
(\%)^{\mathrm{b}}\end{array}$ \\
\hline 1 & Catalyst-free & 25 & 60 & - \\
2 & Catalyst-free & 75 & 60 & - \\
3 & Catalyst-free & 100 & 60 & - \\
4 & 1 & 25 & 8 & 96 \\
5 & 1 & 75 & 8 & 95 \\
6 & 1 & 100 & 8 & 96 \\
7 & 2 & 25 & 8 & 96 \\
8 & 2 & 75 & 10 & 96 \\
9 & 2 & 100 & 10 & 96 \\
10 & 5 & 25 & 15 & 91 \\
11 & 10 & 25 & 15 & 90 \\
\hline
\end{tabular}

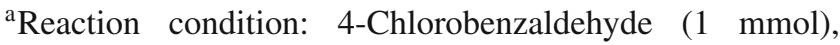
p-toluidine (1 mmol), 5,5-dimethyl-1,3-cyclohexenedione (2 mmol)

${ }^{\mathrm{b}}$ Isolated yield

benign, cheap and a green solvent compared to organic solvents.

To find out the optimum quantity of [2-MPyH]OTf, the reaction of 5,5-dimethylcyclohexane-1,3-dione, 4chlorobenzaldehyde and $p$-toluidine was carried out in water solvent using different quantities of [2MPyH]OTf (table 3). IL [2-MPyH]OTf as a catalyst of $1 \mathrm{~mol} \%$ gave excellent yield in $8 \mathrm{~min}$ as from table 3 . To optimize the temperature in the mentioned reaction, we have carried out a model study with 5,5dimethylcyclohexane-1,3-dione, 4-chlorobenzaldehyde and $p$-toluidine using $1 \mathrm{~mol} \%$ of catalyst at various temperatures in water solvent. Table 3 clearly demonstrates that $25^{\circ} \mathrm{C}$ is an effective temperature in terms of reaction time and yield obtained.

\subsection{Reusability of the catalyst}

Reusability of the catalyst is an important advantage and makes them useful in commercial applications. The catalyst plays a crucial role in the success of the reaction in terms of rate and yields. ${ }^{26}$

Table 4. Reusability studies of catalyst for synthesis of compound $4 h^{\mathrm{a}}$.

\begin{tabular}{lccccc}
\hline Number of experiments & Fresh & 1 & 2 & 3 & 4 \\
\hline Isolated yield (\%) & 96 & 95 & 95 & 94 & 94 \\
Catalyst recovery (\%) & 98 & 96 & 95 & 93 & 91 \\
\hline
\end{tabular}

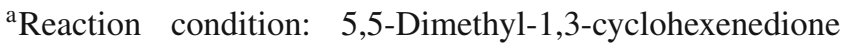
(2 mmol), p-toluidine (1 mmol), 4-chlorobenzaldehyde (1 mmol), ionic liquid catalyst $(1 \mathrm{~mol} \%)$, water solvent $(2 \mathrm{~mL})$

${ }^{\mathrm{b}}$ Isolated yield 
For example, 4-chlorobenzaldehyde reacted with 5,5dimethylcyclohexane-1,3-dione and $p$-toluidine in the presence of $1 \mathrm{~mol} \%$ IL catalyst to give the analogous product in water at room temperature. After completion of the reaction (monitored by TLC), $\mathrm{CH}_{2} \mathrm{Cl}_{2}$ was added to the mixture. The aqueous layer was separated and used without further purification. After washing the solid products with water completely, the water containing ionic liquid (ionic liquid is more soluble in water than $\mathrm{CH}_{2} \mathrm{Cl}_{2}$ ) was evaporated under reduced pressure and the ionic liquid was recovered and reused. The recovered catalyst was reused in five runs without any loss of its activities (table 4). Deactivation of the catalyst is low, although coke formation (reactant) was expected. The reaction was scaled up to $10 \mathrm{mmol}$ of $p$-toluidine and 4-chlorobenzaldehyde and $20 \mathrm{mmol}$ of 5,5-dimethylcyclohexane-1,3-dione in the presence of $10 \mathrm{~mol} \%$ of catalyst at room temperature. Yield of the reaction was $96 \%$ after $8 \mathrm{~min}$ and $94 \%$ after the fifth run. Results are summarized in table 4 .

\subsection{Proposed mechanism}

We propose the following mechanism for the reaction (scheme 2). The IL catalyst changes the aldehyde into convenient electrophile via protonation of the carbonyl<smiles>[R]C1([R])CC(=O)CC(C)C1CC(=O)O</smiles><smiles></smiles><smiles>[R]C1([R])CC(=O)C(=COCC)C(=COCC)C(=O)C1</smiles>

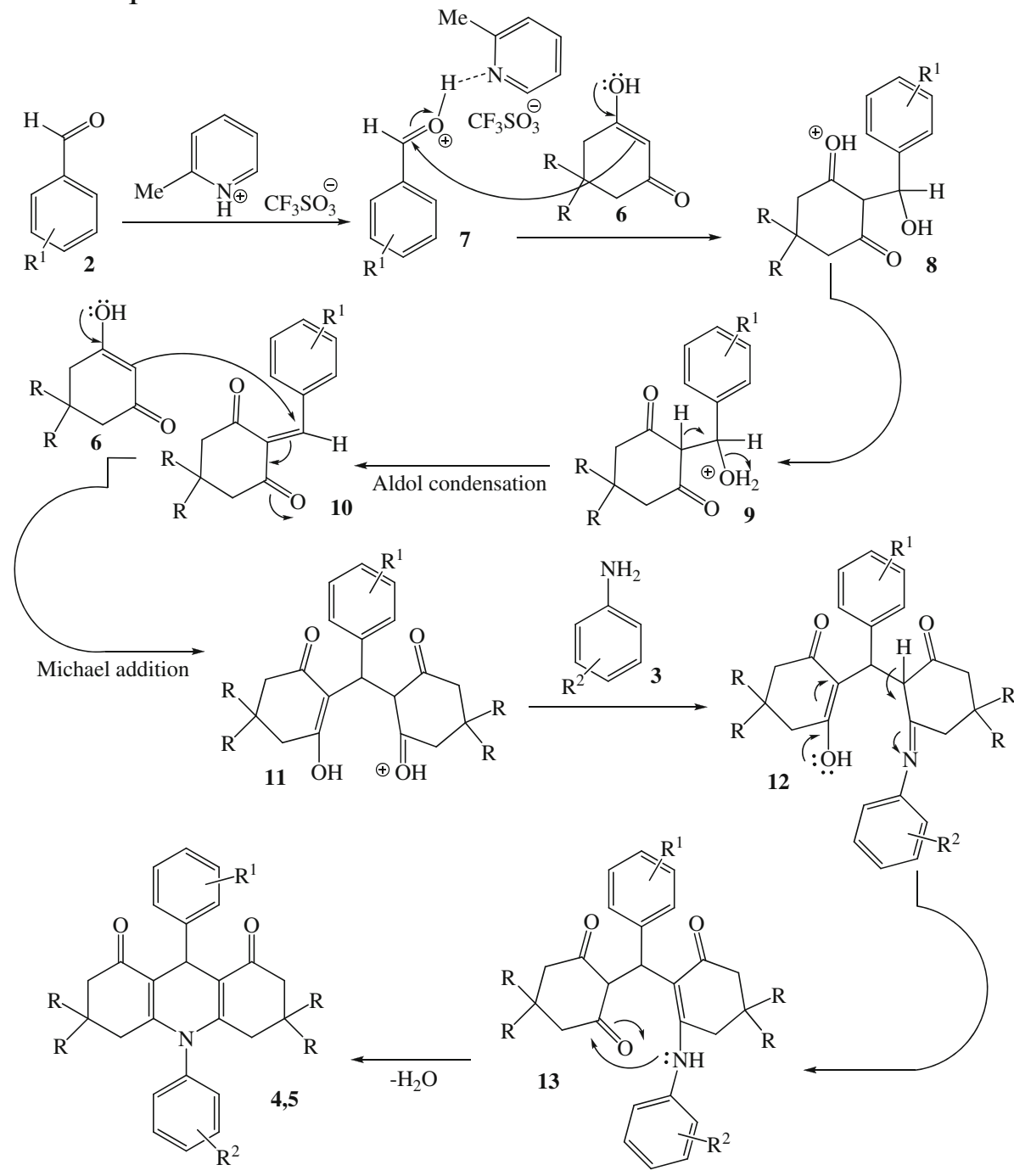

Scheme 2. Proposed mechanism in the synthesis of acridine derivatives using ionic liquid catalyst. 
group and then one molecule of 1,3-dione condenses with the aromatic aldehyde to produce the intermediate compound $\mathbf{1 0}$ (Aldol condensation). Then, the active methylene group of the second molecule of 1,3-dione reacts with 10 to give intermediate 11 (Micheal addition). Nucleophilic attack of amine group of aniline derivatives to carbonyl group creates intermediate 12. In the next step, cyclization will occur by the nucleophilic attack of amine group to carbonyl group to achieve intermediate 13. As a final point, by the removal of one water molecule, the acridine derivatives $\mathbf{4}$ and $\mathbf{5}$ will be produced.

\section{Conclusion}

In summary, IL catalyst was used as a highly efficient and green catalyst for the synthesis of 1,8dioxodecahydroacridine derivatives which resulted to better yields. IL effectively catalyses the reaction of various aldehydes, 1,3-dione and aniline derivatives in water to produce 1,8-dioxodecahydroacridine derivatives in good to excellent yields. The catalyst offers several advantages including non-toxic, mild reaction conditions, cleaner reactions, high yield of the products, shorter reaction times, lower catalytic loading as well as simple experimental and isolation procedures. Also, the catalyst could be reused easily five times with a small decrease in catalytic activity of the recovered catalyst.

\section{Acknowledgement}

This research was supported by the Make Inquiries Commission of the University of Payame Noor, Sari, Iran.

\section{References}

1. Zhao D, Wu M, Kou Y and Min E 2002 Catal. Today 74 157

2. Lu W, Fadaev A G, Qu B, Smela E, Mattes B R, Ding J, Spinks G M, Mazurkiewicz J, Zhou D, Wallace G G, Mac Farlane D R, Forsyth S A and Forsyth M 2002 Science 297983

3. Welton T 2004 Coord. Chem. Rev. 2482459

4. Bhatt A I, Mechler A, Martin L L and Bond A M 2007 J. Mater. Chem. 172241

5. Liu J F, Jonsson J A and Jiang J B 2005 Trends. Anal. Chem. 2420

6. Wang R, Okajima T, Kitamura F and Ohsaka T 2004 Electroanalysis $\mathbf{1 6} 66$

7. Liu J F, Jo L, Wang M, Li Z, Liu H and Li J 2005 Green Chem. 7655
8. Bicak N 2005 J. Mol. Liq. 11615

9. Kidwai M and Bahatnagar D 2010 Chem. Papers 64825

10. Kimura M, Kato A and Okabayashi I 1992 J. Heterocycl. Chem. 2973

11. Josephrajan $\mathrm{T}$, Ramakrishanan $\mathrm{V} \mathrm{T}$ and Muthumary $\mathrm{J}$ 2005 ARKIVOC xi 124

12. Heald R A and Stevens M F G 2003 Org. Biomol. Chem. 13377

13. Michon V and Tombret F 1995 Eur. J. Med. Chem. 30 147

14. Moskural R, Hoke L and Gaudiana R A 2006 J. Macromol. Sci. Part. A. Pure. Appl. Chem. 431907

15. Kumar A, Sharma S and Srivastave V K 2003 Indian J. Chem. 42B 1779

16. Sondhi S M and Bhattacharjee G 2004 Cent. Eur. J. Chem. 21

17. Gutsulyak Kh V, Manzhara V S, Melnik M V and Kalin T I 2005 J. Appl. Spect. 72488

18. Papagni A, Campiglio P and Campione M 2008 J. Fluor. Chem. 129294

19. Subba B V, Antony A and Yadav J S 2010 Tetrahedron Lett. 513071

20. Bakibaev A A, Fillimonov V D and Nevgodova E S 1991 Zh. Org. Khim. 271519

21. Kaya M, Yildirir Y and Celik G Y 2011 Med. Chem. Res. 20293

22. Kidwai M and Bhatanagar D 2010 Tetrahedron Lett. 51 2700

23. Suárez M, Loupy A, Salfrán E, Morán L and Rolando E 1999 Heterocycles $\mathbf{5 1} 21$

24. Martin N, Quinteiro M, Seoane C, Soto J L, Mora A, Suarez M, Morales A, Ochoa E and Bosque J D 1995 J. Heterocycl. Chem. 32235

25. Das B, Thirupathi P, Mahender I, Reddy V S and Rao Y K 2006 J. Mol. Catal. A. Chem. 247233

26. Jin T S, Zhang J S, Guo T T, Wang A Q and Li T S 2004 Synthesis 122001

27. Wang X S, Shi D Q, Zhang Y F, Wang S H and Tu S J 2004 Chin. J. Org. Chem. 24430

28. Li Y L, Zhang M M, Wang X S, Shi D Q, Tu S J, Wei X $\mathrm{Y}$ and Zong Z M 2005 J. Chem. Res. S. 600

29. Wang G W, Xia J J, Miao C B and Wu X L 2006 Bull. Chem. Soc. Jpn. 79454

30. Wang X S, Zhang M M, Jiang H, Shi D Q, Tu S J, Wei X Y and Zong Z M 2006 Synthesis 244187

31. Shen W, Wang L M, Tian H, Tang J and Yu J J 2009 J. Fluor. Chem. 130522

32. Dabiri M, Baghbanzadeh M and Arzroomchilar E 2008 Catal. Commun. 9939

33. Li C J and Chan T H 1997 Organic reaction in aqueous media (New York: Wiley)

34. Duan Z, Gu Y, Zhang J, Zhu L and Deng Y 2006 J. Mol. Catal. A. Chem. 250163

35. Vahdat S M, Mardani H R, Golchoubian H, Khavarpour M, Baghery S and Roshankouhi Z 2013 Comb. Chem. High. T. Scr. 162

36. Venkatesan K, Pujari S S and Srinivasan K V 2009 Synth. Commun. 39228

37. Chandrasekhar S, Rao Y S, Sreelakshmi L, Mahipal B and Reddy C R 2008 Synthesis 111737 